\title{
Geociências
}

\section{A suíte metatholeiítica da seqüência metavulcanos- sedimentar Rio Manso, Quadrilátero Ferrífero (MG)}

\author{
(The metatholeiitic suite of the Rio Manso \\ metavolcanosedimentary sequence, Iron \\ Quadrangle (MG))
}

\section{Resumo}

A seqüência metavulcanossedimentar Rio Manso compreende rochas metaultramáficas com intercalações de metamafitos e rochas metassedimentares psamo-pelíticas. Localiza-se no domínio geológico do Quadrilátero Ferrífero em Minas Gerais, porção meridional do Cráton São Francisco. O mapeamento litoestrutural (escala 1:10.000) assim como os estudos petrográficos, mineralógicos e litogeoquímicos permitiram identificar, no âmbito dessa seqüência, uma Suíte Metatholeiítica. Em termos geoquímicos, se comparada com outras ocorrências mundiais, a Seqüência Metavulcanossedimentar Rio Manso se assemelha à Seqüência Mesoarqueana de Barbeton. Essa semelhança sugere que a Seqüência estudada corresponde a um terreno granito-greenstone que poderia representar a continuidade nordeste do Complexo Metamórfico Campo Belo de idade mesoarqueana.

Palavras-chave: Metaultramafitos, Quadrilátero Ferrífero, seqüência metavulcanossedimentar de Rio Manso, arqueano.

\section{Gorki Pomar Andreatta e Silva}

Departamento de Geologia, Escola de Minas, Universidade Federal de Ouro

Preto-PPECRN

E-mail:gorkiearth@hotmail.com

\section{Mauricio Antônio Carneiro}

Departamento de Geologia, Escola de Minas, Universidade Federal de Ouro

Preto-PPECRN

E-mail:mauricio@degeo.ufop.br

\section{Abstract}

The Rio Manso Metavolcanosedimentary Sequence comprises metaultramafic rocks with intercalations of metamafic and psammo-pelitic metasedimentary rocks located in the geologic domain of the Iron Quadrangle in Minas Gerais, southern São Francisco Craton. The litho-structural mapping (1:10,000), as well as petrographic, mineralogical and lithogeochemical studies allowed the identification of a metatholeiitic suite in the range of this sequence. When compared to other world sequences in terms of geochemistry, the Rio Manso Metavolcanosedimentary Sequence is similar to the Mesoarchean Barbeton Sequence. This similarity suggests that the studied Sequence corresponds to a granite-greenstone terrain which may represent the northeastern extension of the Mesoarchean Campo Belo Metamorphic Complex.

Keywords: Metaultramafites, Iron Quadrangle, Rio Manso, metavolcanosedimentary sequence, archean. 


\section{Introdução}

Apresentam-se, nesse trabalho, os resultados de um estudo geológico realizado na seqüência metavulcanossedimentar Rio Manso, que compreendeu mapeamento geológico (1:10.000), petrologia, minerografia e litogeoquímica. Essa seqüência, doravante designada como SMRM, ocorre nas proximidades da cidade de Rio Manso, no domínio geológico do Quadrilátero Ferrífero em Minas Gerais (Figura 1) e compreende um cinturão de rochas metaultramáficas com intercalações de metamafitos e metassedimentos de natureza psamo-pelítica.

O conhecimento geológico acerca da SMRM é escasso, destacando-se o trabalho de Pinheiro (1998), que relata a existência de rochas vulcânicas (com e sem textura spinifex) e a presença de derrames maciços e acamadados, com variadas texturas e estruturas ígneas. Tectonicamente, a SMRM está inserida no contexto do Cráton São Francisco Meridional e compreende: 1) uma crosta siálica (Carneiro 1992; Teixeira et al. 2000) estabilizada no Neoarqueano (e.g. Complexo Metamórfico Campo Belo); 2) seqüências supracrustais arqueanas (Supergrupo Rio das Velhas - Dorr II, 1969; Schorscher et al., 1982, Ladeira, 1980, 1981, 1988) e 3) seqüências supracrustais proterozóicas (e.g. Supergrupo Minas - Dorr II, 1969). O Supergrupo Rio das Velhas é uma seqüência metavulcanossedimentar do tipo greenstone belt, constituída, da base para o topo, pelos grupos Quebra Ossos, Nova Lima e Maquiné (Dorr II, 1969, Schorscher et

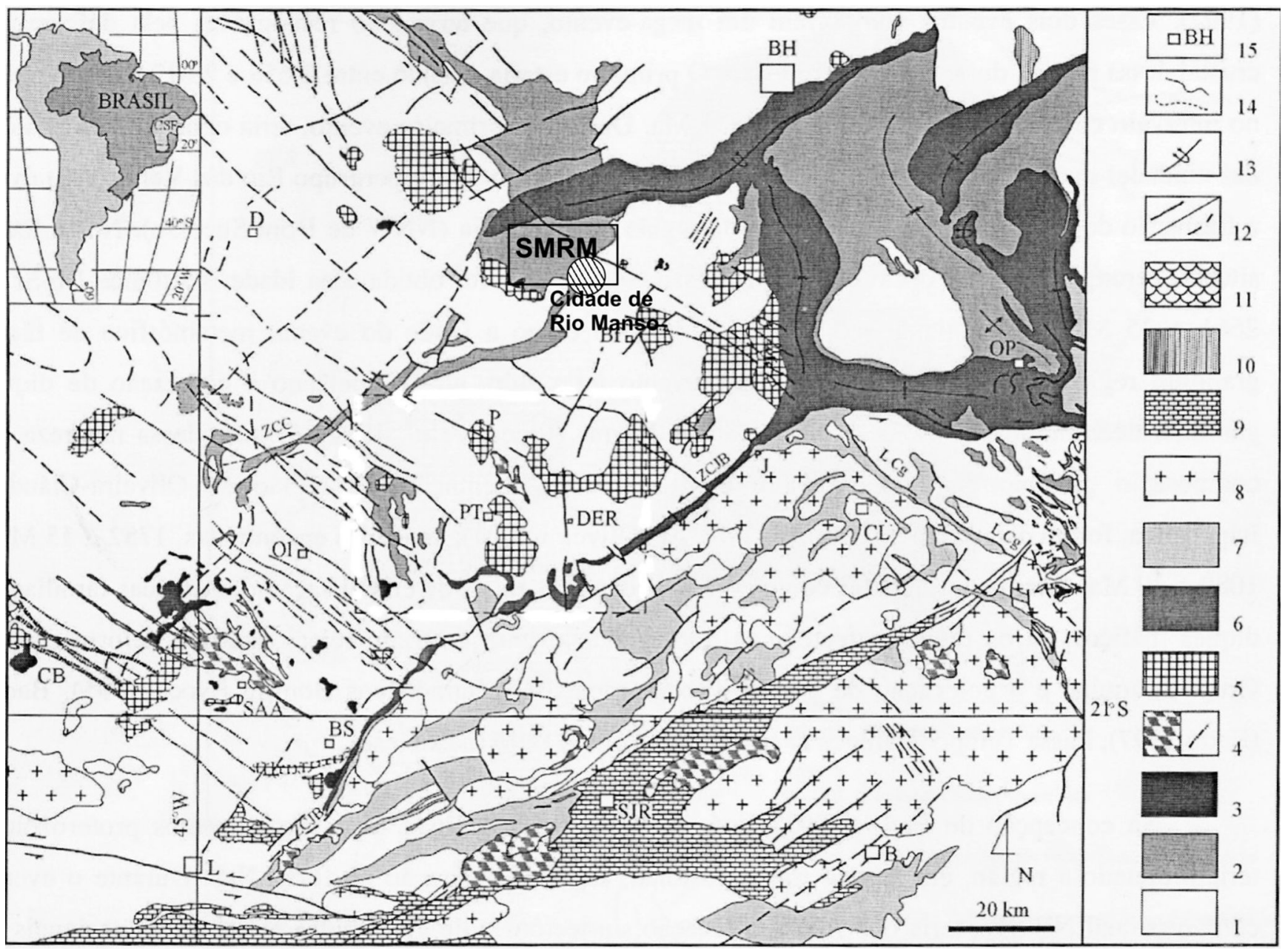

Figura 1 - Geologia da porção meridional do Cráton São Francisco, modificado de Campos (2004). 1 = Terrenos Arqueanos e Paleoproterozóicos Indiferenciados; 2 = Seqüências greenstone arqueanas [Supergrupo Rio das Velhas e Correlatos]; 3 = Suítes Máfico-Ultramáficas [Ribeirão dos Motas e Correlatos]; 4 = Rochas Gabróicas e Dioríticas Indiferenciadas; $5=$ Granitóides Arqueanos, 6 = Supergrupo Minas; 7 = Seqüências tipo greenstone indiferenciadas (Proterozóico); 8 = Granitóides Proterozóicos; 9 = Grupos São João del-Rey e Andrelândia; 10 = Supergrupo Espinhaço, e 11 - Cobertura Cratônica Indivisa; 12 = Falhas e Lineamentos (ZCC - Zona de Cisalhamento Cláudio, ZCJB - Zona de Cisalhamento Jeceaba-Bom Sucesso, LCg - Lineamento Congonhas); 13 = Eixos de Dobras; 14 = A) Traço das Foliações Regionais, B) Contatos Geológicos; 15 = Cidades: B) Barbacena, Bf) Bonfim, BH) Belo Horizonte, BS) Bom Sucesso, CB) Campo Belo, CL) Conselheiro Lafaiete, D) Divinópolis, DER) Desterro de Entre Rios, L) Lavras, OI) Oliveira, OP) Ouro Preto, PT) Passa Tempo, SAA) Santo Antônio do Amparo, SJR) São João del-Rey. SMRM - Área de ocorrência da Seqüência Metavulcanossedimentar Rio Manso. 
al., 1982, Ladeira, 1980, 1981, 1988). O principal evento tectônico imposto a essa seqüência é do Neoarqueano e teve lugar à volta de $2,78 \mathrm{Ga}$ (Machado \& Carneiro, 1992). Com relação à ocorrência de ultramafitos na região, Harder e Chamberlain (1915) foram os pioneiros na caracterização desses litotipos no Quadrilátero Ferrífero, que, posteriormente, foram classificados em tipos intrusivos e extrusivos (Maxwell, 1972). Schorscher (1978) identificou texturas spinifex nos ultramafitos extrusivos, classificando-os como lavas metaultramáficas komatíticas e propondo a sua inclusão, juntamente com os metabasaltos e metassedimentos, na base do Supergrupo Rio das Velhas. Com isso, formalizou-se o Grupo Quebra Ossos (Sichel \& Valença, 1983). Regionalmente citam-se, também, os metaultramafitos do Córrego dos Boiadeiros (Gair, 1962, Pomerene, 1964, Padilha, 1984, Padilha et al., 1985, 1991, Costa, 1995); Tinguá-Caeté (Souza Filho 1991, Oliveira, 1986); Lafaiete (Pires, 1977; Schorscher et al., 1982; Seixas, 1988); Itaguara (Goulart, 2006), Ribeirão dos Motas (Carneiro, 1966, Carneiro et al., 1997, Oliveira, 1999, Carvalho Jr., 2001; Oliveira, 2004, Fernandes, 2001); Itapecerica (Oliveira, 1999); Cláudio (Couto 2004; Couto \& Carneiro, 2007); Morro das Almas (Quéméneur \& Baraud 1983; Barbosa et al., 1996). O Complexo Metamórfico Campo Belo configura-se como um segmento de crosta siálica que possui numerosas ocorrências de rochas ultramáficas contendo feições plutônicas e regionalmente correlacionadas à Sequência Acamadada Ribeirão dos Motas. Esse complexo se diferencia do Complexo Metamórfico Barbacena pela presença de granitóides cisalhados, enclaves anfibolíticos, enxames de diques máficos e plútons máficos não acamadados (Machado Filho et al., 1983). Por outro lado, o Complexo Metamórfico Barbacena apresenta metatexitos com paleossomas de xistos básicos e ultrabásicos e neossomas granodioríticos de idade arqueana, porém retrabalhados parcialmente pelo ciclo transamazônico. Além disso, charnockitos, anfibolitos, magnetititos e gnaisses facoidais possuem ocorrência restrita nesse complexo. As- sim sendo, Teixeira et al. (1996) denominaram de Complexo Metamórfico Campo Belo toda a crosta siálica a oeste do Complexo Metamórfico Bonfim na região do Quadrilátero Ferrífero, de forma a diferenciar duas grandes crostas arqueanas de história evolutiva polifásica.

\section{Materiais e métodos}

O mapeamento geológico e os estudos petrográficos, minerográficos, petrológicos e litogeoquímicos realizados na SMRM abarcaram, além da área estudada por Pinheiro (1998), a continuidade setentrional dessa seqüência, localizada a oeste da sede da cidade de Rio Manso (Figura 1). No caso dos estudos litogeoquímicos, antecedendo a preparação propriamente dita das amostras em laboratório, alguns procedimentos foram realizados no campo. Para evitar contaminação do material a ser analisado, as crostas intemperizadas, ou porções inadequadas, foram removidas a golpes de marreta. Na impossibilidade dessa remoção in situ, utilizou-se, em laboratório, de uma serra circular diamantada para fatiar e remover as porções isentas de intemperismo, que foram, então, cominuídas, quarteadas, pulverizadas e armazenadas em pequenos pacotes lacrados de $50 \mathrm{~g}$. As análises litogeoquímicas foram realizadas pela ACME ANALYTICAL LABORATORIES LTD. que, após, o processo-padrão de abertura das amostras com base em ataque ácido e fusão alcalina, realizou as análises litogeoquímicas para elementos maiores via ICP-ES e traços via ICP-MS (elementos maiores em porcentagem em peso) e traços em partes por milhão. Os limites de detecção são da ordem de $0,01 \%$ para óxidos e de $0,1 \mathrm{ppm}$ para elementos-traço e 0,01 para REE. No tratamento dos dados litogeoquímicos, utilizou-se o software MINPET 2.0, a partir de tabelas geradas em Microsoft EXCEL.

\section{Resultados}

Constatou-se que, nos domínios da SMRM, afloram, principalmente, metavulcanitos formados por tipos texturais e estruturais diversos (Figura 2), destacando topos enrugados pelo arrefecimento brusco de magmas viscosos e truncamentos vulcânicos (Figura 2C). Numerosos afloramentos exibem acamamentos ígneos destacados pela ação deutérica seletiva, que é mais pronunciada nos níveis peridotíticos e piroxeníticos, geralmente situados na base e no topo dos derrames. Os acamamentos ígneos podem ser facilmente caracterizados através da textura e granulação dos minerais, sendo confirmados pela presença de sulcos (depressões) e protuberâncias, referentes às partes basais e de topo dos derrames, respectivamente. Nos metavulcanitos, o acamamento é irregular, devido ao resfriamento rápido, mas, nos metaplutonitos, é perfeitamente plano. Quanto às texturas, destacamse a cumulática, que nos derrames configura-se como um nível basal de peridotito, e o nível de topo mais piroxenítico, que pode conter as texturas: spinifex (Figuras 2A e 2B); brechas de topo e textura vítrea ou amorfa. Tais feições texturais permitem obter informações geopetais. Adicionalmente relata-se a presença de fraturas de resfriamento e, ainda, tubos de lava circundados por almofadas e auréolas de textura spinifex, pequenos plugs circundados por junções poliédricas, além de derrames maciços correlacionadas aos tipos petrográficos "b" e "c" de Arndt et al. (1977). O tipo "b" apresenta peridotito maciço na base com feição isotrópica, uma zona intermediária delgada com textura spinifex e uma zona de topo com textura vítrea, brechas de topo e enrugamentos. O tipo "c" apresenta uma espessa porção basal de peridotito maciço e uma delgada zona de topo com textura vítrea, brechas de topo e enrugamentos.

Originalmente, Pinheiro (1998) englobou esses litotipos na suíte metakomatíitica. Todavia, introduz-se, agora, uma nova suíte, caracterizada petrograficamente por augita-xistos e clorita-xistos. Os augita-xistos se diferenciam dos clorita-xistos por sua granulação grosseira e ripas de piroxênio com clivagem 
basal em seção delgada. Ambos possuem teor de $\mathrm{MgO}$ ligeiramente inferior a 10\%, revelando uma gênese compatível com a série tholeiítica. Em diagramas ternários AFM, as rochas dessa suíte revelam uma composição química compatível com a Série Tholeiítica (Andreatta e Silva 2008), tratando-se, portanto, de Mg-metatholeiítos e, doravante, esses litotipos serão englobados na suíte metatholeítica. Quimicamente, essa suíte é caracterizada por um conteúdo de $\mathrm{MgO}$ menor que $12 \%$, com $\mathrm{TiO}_{2}$ menor que $2,4 \%$ e baixas razões $\mathrm{FeO} / \mathrm{MgO}$ (Andreatta e Silva, 2008). Utilizandose do padrão terras raras (Figura 3, Tabela 1), é possível distinguir, com clareza, as suítes metakomatítica e metatholeiítica da SMRM. Essas suítes mostram padrões de fracionamento similar, mas a série metatholeíitica tem um padrão mais enriquecido. Essas características também estão expressas em outros diagramas geoquímicos (e.g. $\mathrm{SiO}_{2} \times \mathrm{MgO}, \mathrm{Zr} \times \mathrm{TiO}_{2} ;$ Andreatta e Silva, 2008). Localmente, os metatholeí́tos basais apresentam até $2 \%$ em sulfetos, que, estudados sob luz refletida (Andreatta e Silva, 2008), revelaram a ocorrência de três fases de cristalização seqüenciais. A fase 1 apresenta magnetita envolvida por pirrotita. $\mathrm{Na}$ fase 2, a pirita envolve a pirrotita e, na fase 3 , a calcopirita envolve a pirita.

\section{Discussão}

\subsection{Aspectos petrográficos e minerográficos gerais da SMRM}

A inexistência de lavas almofadadas na suíte metatholeiítica da SMRM implica, necessariamente, condições de terras emersas pela ascensão vertical da pilha vulcânica. Outra possibilidade implicaria recuo do nível do mar, no qual a quebra de relevo, entre a plataforma continental e o sopé do talude continental, causaria um entulhamento de sedimentos grosseiros gerados em alta energia. Nesse caso, rochas conglomeráticas seriam preservadas na SMRM, fato, porém, não observado. Por outro lado, os
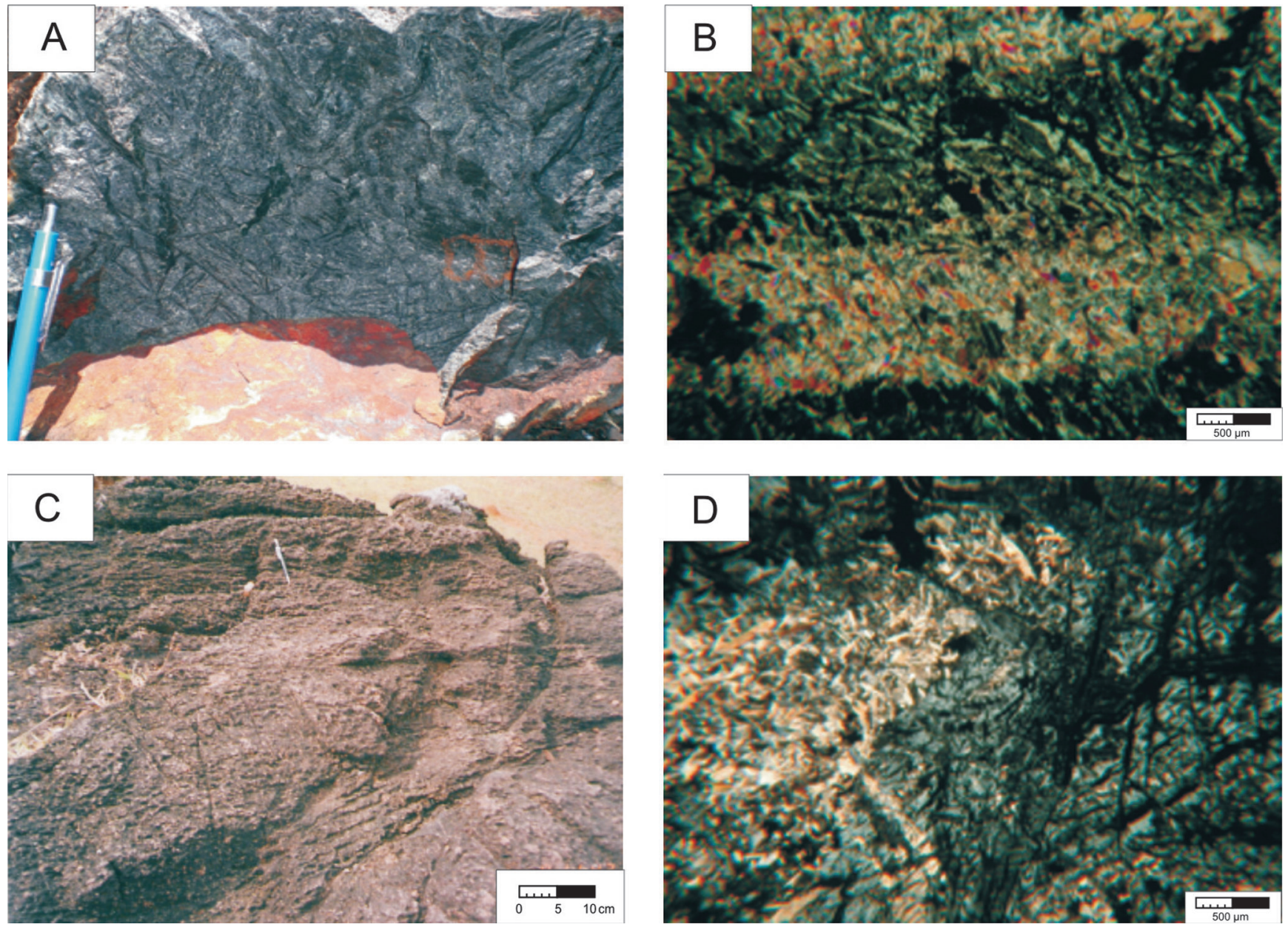

Figura 2 - Algumas feições macroscópicas e microscópicas da SMRM. A) Metaultramafito exibindo textura spinifex; B) Metaultramafito com textura spinifex, calcificado, exibindo transformações para serpentina, opacos e anfibólios; C) Afloramento exibindo truncamento de derrame em regime de extravasamento contínuo; D) Metaultramafito com textura jack-straw formando polígonos fechados devido ao metamorfismo seletivo com a formação de trilhas de antofilita entre serpentina e opacos. 
litotipos estudados da SMRM exibem texturas cumuláticas atribuídas a extravasamento contínuo contendo truncamentos, que revelam a ocorrência de diversos canais alimentadores. Esses canais transicionam para derrames maciços com extravasamento contínuo de derrames magnesianos com textura spinifex, típicos dos derrames basais de greenstone belts. Analisando em separado a base da pilha vulcânica metatholeiítica com cerca de 65 derrames e 50 metros de espessura, encontram-se litotipos de textura fanerítica além de certa planaridade no acamamento como efeito de um aumento da viscosidade (McBirney \& Hunter, 1995), que poderia indicar um certo potencial metalogenético para a formação de sulfetos em rede. Contudo a SMRM não possui sedimentos sulfurosos interderrames e, além disso, a porcentagem de minerais sulfetados é pequena (2\%), indicando que a seqüência pode ser insaturada em enxofre. Se fosse assim, não teria ocorrido a segregação de fases sulfetadas significativas (Lesher et al., 2001), ou, ainda, tais fases poderiam ter migrado, gerando um minério disseminado e/ou trapeado no decorrer dos eventos durante e/ ou após a formação da SMRM.

\subsection{Aspectos litogeoquímicos da SMRM}

De acordo com Arndt \& Nisbet (1982), uma suíte tholeiítica é caracterizada, invariavelmente, por conteúdos de $\mathrm{MgO}$ inferiores a 7\%. Somente os cumulatos piroxeníticos de Munro Township, referentes ao clã dos basaltos komatíticos, possuem $\mathrm{MgO}$ acima de $15,5 \%$ (Arndt et al., 1977). Por outro lado, Munro Township se caracteriza por um substrato formado por basaltos tholeiíticos com uma porcentagem de $\mathrm{MgO}$ ligeiramente inferior a $10 \% \mathrm{MgO}$ (Arndt et al., 1977). Esses basaltos tholeiíticos, no entanto, contêm plagioclásio, mineral que, por sua vez, está ausente nas rochas da SMRM. Assim, de acordo com Andreatta e Silva (2008), o comportamento geoquímico da SMRM permite concluir que os metakomatítos e metatho-

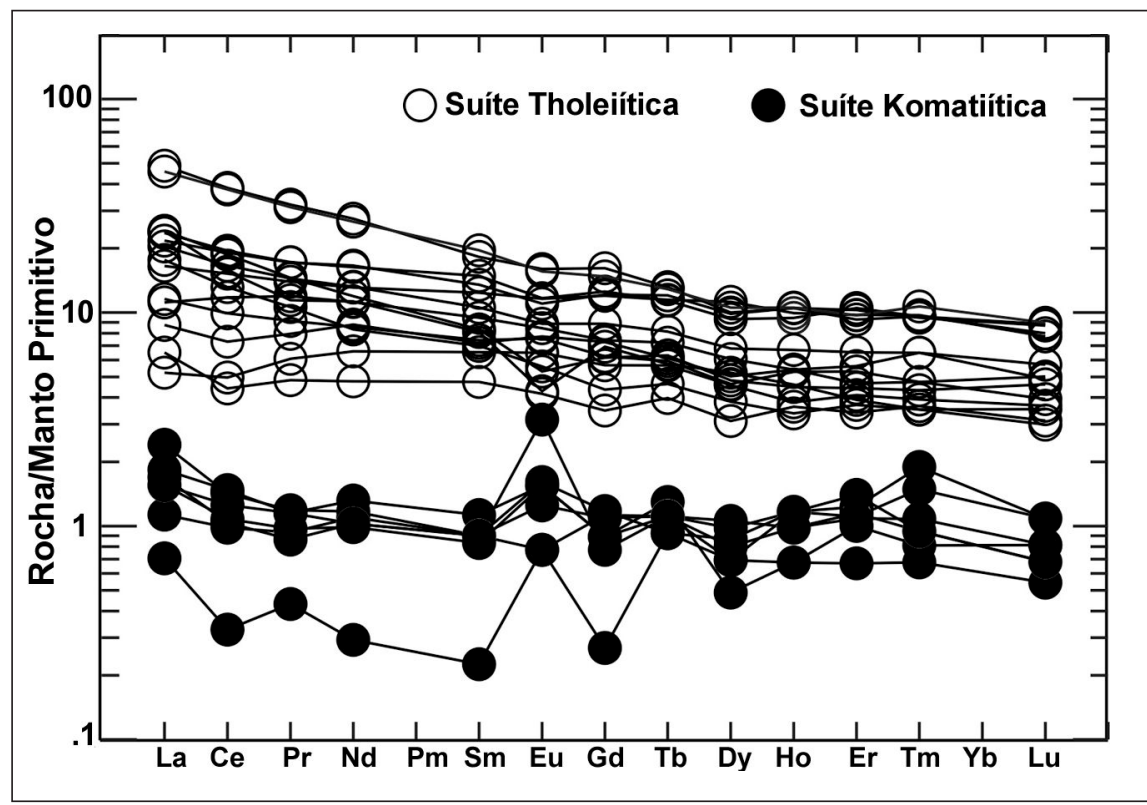

Figura 3 - Padrão de REE (normalizado pelo manto primitivo de McDonough et al., 1992) das Suítes Metakomatítica e Metatholeiítica da SMRM, exibindo o fracionamento magmático e o aspecto cogenético das suas rochas.

leiítos possuem uma gênese comum e distribuição areal associada, ou seja, o fracionamento e a assimilação crustal do magma komatíitico primordial geraram os basaltos tholeiíticos de greenstone, permitindo, assim, caracterizar um ciclo vulcânico intermediário, na SMRM, como produto de intensa assimilação crustal. (Tabela 1).

\section{Conclusões}

Apesar de Pinheiro (1998) ter considerado dois grupos de rochas na suíte metakomatíitica (com e sem textura spinifex), constatou-se que a grande maioria dos metaultramafitos estudados não apresenta tais texturas. Quando presentes, as texturas spinifex reliquiares (Figura 2B) são representadas por placas de olivina serpentinizada contendo trilhas de opacos. É notável a diferença entre as texturas spinifex em amostra de mão e em lâmina. Isso se deve à presença de trilhas de ortoanfibólio e serpentina. No caso específico da olivina serpentinizada, foram encontrados pseudomorfos de olivinas placosas e poliédricas na SMRM. Nas amostras onde ocorrem os pseudomorfos de olivina placosa, com trilhas de opacos em seu interi- or, destaca-se também a ocorrência da textura pega-varetas (ou jack-straw), cujos ramos formam polígonos fechados (Figura 2D). Os pseudomorfos de olivina poliédrica são caracterizados por cristais eqüidimensionais e tabulares, idioblásticos, sem embainhamento. Em termos geoquímicos, se comparada com outras ocorrências mundiais, a SMRM se assemelha à seqüência de Barbeton, ou seja, seria fracionada regionalmente pela existência de uma superpluma e encaixada em uma crosta siálica primitiva. Essa seria a única explicação plausível para a suíte metatholeiítica da SMRM, fato que muito se diferencia de ciclos vulcânicos completos, comuns em greenstones superiores encaixados em crostas siálicas empobrecidas, como é o caso do greenstone belt Rio das Velhas. Assim, a ocorrência da suíte metatholeítica na SMRM, que, microscopicamente, não possui plagioclásio, reforça a correlação com as séries tholeiíticas da região das montanhas de Barberton, mais precisamente com o Cinturão Pietersburg (Grobler, 1972; Hart \& Brooks, 1977; Jensen \& Pyke, 1982). Por outro lado, se a SMRM tivesse correlação com ocorrências greenstones mais recentes haveria a repetição de ciclos vulcânicos 
A suíte metatholeiítica da seqüência metavulcanossedimentar Rio Manso, Quadrilátero Ferrífero (MG)

Tabela 1 - Composição química em termos de REE de rochas das Suítes Metakomatí́tica e Metatholeiítica da SMRM.

\begin{tabular}{l|c|c|c|c|c|c|c|c|c|c|c|c|c|c}
\hline Amostras & La & Ce & Pr & Nd & Sm & Eu & Gd & Tb & Dy & Ho & Er & Tm & Lu \\
\hline \multicolumn{10}{c}{ SUÍTE METATHOLEIITICA } \\
\hline 54 FE 72 & 8.2 & 18.2 & 2.54 & 11.7 & 3.3 & 1.27 & 3.71 & 0.64 & 3.41 & 0.86 & 2.54 & 0.35 & 0.37 \\
\hline 54 EB 02 & 7.9 & 21.6 & 3.32 & 15.3 & 4.2 & 1.42 & 4.41 & 0.78 & 4.47 & 0.88 & 2.69 & 0.48 & 0.36 \\
\hline 54 EB 11 & 12.5 & 24.1 & 2.95 & 11.4 & 3.1 & 0.94 & 2.59 & 0.5 & 2.82 & 0.55 & 1.77 & 0.26 & 0.26 \\
\hline 54 EE 54 & 34.5 & 70.4 & 8.92 & 37.6 & 8.1 & 2.69 & 9.61 & 1.42 & 7.38 & 1.71 & 4.44 & 0.71 & 0.59 \\
\hline 54 EB 05A & 16.7 & 35.7 & 4.79 & 22.3 & 6.6 & 1.96 & 7.46 & 1.23 & 6.86 & 1.54 & 5.03 & 0.71 & 0.65 \\
\hline 54 EB 05 & 15.4 & 35 & 4.77 & 22.7 & 6 & 1.85 & 7.23 & 1.3 & 7.27 & 1.71 & 4.92 & 0.7 & 0.64 \\
\hline 54 FE 85 & 11.7 & 27.9 & 3.88 & 17.9 & 5.5 & 1.95 & 7.13 & 1.24 & 8.28 & 1.62 & 4.67 & 0.72 & 0.57 \\
\hline 54 FC 13A & 6.2 & 13.4 & 2.21 & 12 & 3.2 & 1.3 & 4.33 & 0.66 & 3.71 & 0.88 & 2.23 & 0.35 & 0.29 \\
\hline 54 FC 13B & 3.7 & 9.1 & 1.69 & 9 & 2.9 & 1.09 & 3.37 & 0.61 & 3.37 & 0.62 & 1.97 & 0.29 & 0.27 \\
\hline 54 FE 04 & 4.6 & 8.1 & 1.34 & 6.5 & 2.1 & 0.7 & 2.07 & 0.43 & 2.29 & 0.59 & 1.63 & 0.27 & 0.23 \\
\hline 54 EE 52 & 32.4 & 69.1 & 8.66 & 36.4 & 8.7 & 2.62 & 8.78 & 1.39 & 7.78 & 1.72 & 4.65 & 0.79 & 0.66 \\
\hline 54 DD 09 & 17 & 28.5 & 3.18 & 15.4 & 3.6 & 0.72 & 4.12 & 0.62 & 3.85 & 0.75 & 1.87 & 0.26 & 0.22 \\
\hline 54 FB 02 & 17.1 & 34.3 & 4.04 & 16.3 & 3.7 & 0.89 & 3.66 & 0.68 & 3.55 & 0.73 & 2.12 & 0.32 & 0.34 \\
\hline
\end{tabular}

SUITE METAKOMATIITICA

\begin{tabular}{c|c|c|c|c|c|c|c|c|c|c|c|c|c}
\hline 54 FE 58B & 1.3 & 2.7 & 0.32 & 1.8 & 0.5 & 0.26 & 0.53 & 0.14 & 0.36 & 0.11 & 0.48 & 0.06 & 0.06 \\
\hline 54 FE 22 & 0.5 & 0.6 & 0.12 & 0.4 & 0.1 & 0.13 & 0.16 & 0.1 & 0.51 & 0.11 & 0.32 & 0.05 & 0.04 \\
\hline 54 FD 63 & 1.7 & 2.6 & 0.33 & 1.6 & 0.4 & 0.13 & 0.67 & 0.12 & 0.72 & 0.19 & 0.53 & 0.11 & 0.08 \\
\hline 54 FE 105 & 0.8 & 1.8 & 0.26 & 1.5 & 0.4 & 0.21 & 0.65 & 0.12 & 0.51 & 0.19 & 0.59 & 0.14 & 0.08 \\
\hline 54 FE 71 & 1.1 & 2.3 & 0.32 & 1.4 & 0.4 & 0.53 & 0.46 & 0.12 & 0.78 & 0.16 & 0.55 & 0.07 & 0.05 \\
\hline 54 FE 58A & 1.2 & 1.9 & 0.24 & 1.4 & 0.4 & 0.27 & 0.7 & 0.1 & 0.64 & 0.19 & 0.67 & 0.07 & 0.05 \\
\hline
\end{tabular}

completos e até mesmo conglomerados de topo, feições ausentes em greenstones intermediários. Conseqüentemente, devido ao posicionamento do Supergrupo Rio das Velhas como seqüência greenstone superior do Neoarqueano, a presença da SMRM no âmbito do Quadrilátero Ferrífero remete à continuidade geológica do Complexo Metamórfico Campo Belo até essa região, sob a forma de um terreno granito-greenstone do Mesoarqueano como argumentado por vários autores (e.g. Barbosa et al., 1996; Carvalho Jr., 2001, Couto, 2004; Fernandes, 2001; Oliveira, 1999; Oliveira, 2004; Quéméneur $\&$ Baraud, 1983). Finalmente, com rela- ção ao potencial econômico mineral, essa ocorrência seria, aparentemente, estéril em sulfetos maciços vulcanogênicos, devido à existência de disseminação basal na pilha tholeiítica. Todavia, ocorrendo ou não níveis sulfetados em rede ou maciços na SMRM, são necessários estudos mais detalhados sobre esse assunto.

\section{Referências bibliográficas}

ANDREATTA E SILVA, G. P. A seqüência metavulcanossedimentar arqueana Rio Manso, Complexo metamórfico Campo
Belo Setentrional, MG. Ouro Preto: Departamento de Geologia, Universidade Federal de Ouro Preto, 2008. 89p. (Dissertação de Mestrado).

ARNDT, N. T., NALDRETT, A. J., PYKE, D. R. Komatiitic and iron-rich tholeiitic lavas of Munro Township, Northeast Ontario. Journal of Petrology, v. 18, p. 319-69, 1977.

ARNDT, N. T., NISBET, E. G. Komatiites. London: George Allen \& Unwin, 1982. $526 \mathrm{p}$.

BARBOSA, M. I. M., PIRES, F. R. M., NILSON, A. A. Geologia do Complexo Ultramáfico Morro das Almas, Região de Bom Sucesso e Ibituruna, MG. In: CONGR. BRAS. GEOL., 39. Anais... Natal: SBG, 1996. p. 209-211. 
Gorki Pomar Andreatta e Silva et al.

CARNEIRO, M. A. O complexo metamórfico Bonfim Setentrional Quadrilátero Ferrífero, Minas Gerais: litoestratigrafia e evolução geológica de um segmento de continental do arqueano. São Paulo: Instituto de Geociências, Universidade de São Paulo, 1992. 233p. (Tese de Doutorado).

CARNEIRO, M. A., TEIXEIRA, W., NALINI JR., H. A., BILAL, E., OLIVEIRA, A. H., CARVALHO JR., I. M. Archean ultramafic-mafic magmatism in the southern São Francisco Craton, Campo Belo Complex: preliminary petrografic and geochemical results. In: SYMPOSIUM OF ARCHEAN TERRANES OF THE SOUTH AMERICAN PLATFORM. Extend Abstracts... Brasília: SBG, 1966. p. 3233.

CARNEIRO, M. A., NALINI JR, H. A., BILAL, E., CARVALHO JR, I. M., TEIXEIRA, W., MOUTTE, J. A seqüência Acamadada de Ribeirão dos Motas, Minas Gerais, Brasil. In: SEMANA DE GEOQUÍMICA, 10, CONGRESSO DE GEOQUÍMICA DOS PAÍSES DE LÍNGUA PORTUGUESA, 4. Actas... Braga: 1997. v. 1, p. 31-33

CARvalho Jr., I. M. Petrologia $\boldsymbol{e}$ geoquímica de rochas máficas $e$ ultramáficas arqueanas do Cráton São Francisco Meridional: a Seqüência Acamada Ribeirão dos Motas, Minas Gerais. Ouro Preto: Departamento de Geologia, Universidade Federal de Ouro Preto, 2001. 97p. (Dissertação de Mestrado).

COSTA, C. S. Petrogênese do corpo metaultramáfico do Córrego dos Boiadeiros, Quadrilátero Ferrífero, Minas Gerais, MG. Belo Horizonte: IGC, Universidade Federal de Minas Gerais, 1995. 172p. (Dissertação de Mestrado).

COUTO, D. J. F. Petrogênese dos metaultramafitos e mafitos da região de Cláudio (MG). Ouro Preto: Departamento de Geologia, Universidade Federal de Ouro Preto, 2004. 173p. (Dissertação de Mestrado).

COUTO, D. J. F., CARNEIRO, M. A. The Genesis Of The Metaultramafites From Cláudio (Mg). Geochimica Brasiliensis, v. 21, p. 9-21, 2007.

DORR, J. V. N. Physiographic, stratigraphic and structural development of the Quadrilátero Ferrífero, Minas Gerais, Brazil. Ouro Preto: DNPM/USGS, 1969. Professional Paper, 110p. (Boletim 641).
FERNANDES, R. A. Etapas de formação de crosta continental do mesoarqueano ao mesoproterozóico no Cráton São Francisco Meridional. Ouro Preto: Departamento de Geologia, Universidade Federal de Ouro Preto, 2001. 127p. (Dissertação de Mestrado).

GAIR, J. E. Geology and ore deposits of the Nova lima and Rio Acima Quadrangles, Minas Gerais, Brazil. Ouro Preto: DNPM/USGS, 1962. Professional Paper, 111p. (Boletim 341-A).

GOULART, L. E. A. A seqüência acamadada Itaguara - Rio Manso, MG. Ouro Preto: Departamento de Geologia, Universidade Federal de Ouro Preto, 2006. 183p. (Dissertação de Mestrado).

GROBLER, N. J. The geology of the Pietersburg greenstone belt. Bloemfontein: University of the Orange Free State, 1972. 201p. (D.Sc. thesis).

HARDER, E. C., CHAMBERLAIN, R. T. Geology of Central Minas Gerais, Brazil. Journal of Geology, v. 23, p. 341-378, 1915.

HART, S. R., BROOKS, C. The geochemistry and evolution of Early Precambrian mantle. Contrib. Mineral. Petrol., v. 61, p. 109-128, 1977.

JENSEN, L. S., PYKE, D. R. Komatiites in the Ontario portion of the Abitibi belt. In: ARNDT, N.T., NISBET, E.G. (ed.). Komatiites. London: George Allen \& Unwin, 1982. cap. 11, p. 147-157. 526p.

LADEIRA, E. A. Primeiras lavas com almofadas (pillows) encontradas no Supergrupo Rio das Velhas, de idade arqueana, no Quadrilátero Ferrífero e no Distrito de Pitangui, Minas Gerais. Revista Ciências da Terra, v. 1, p. 12-14. 1981.

LADEIRA, E. A. Metallogenesis of gold at the Morro Velho mine, and in Nova Lima district, Quadrilátero Ferrífero, Minas Gerais, MG. Ontario: Univ. of Western Ontario, 1980. 274p. (Ph.D. Thesis)

LADEIRA, E. A. Metalogenia dos depósitos de ouro do Quadrilátero Ferrífero, Minas Gerais, Brasil. In: SCHOBBENHAUS, C., COELHO. C. E. S. (ed.). Principais depósitos minerais do Brasil. Metais básicos não ferrosos, ouro e alumínio. Brasília: DNPM, v. 3, cap. 25, p.301375, 1988. 674p.

LESHER, C. M., BURNHAM, O. M., KEAYS, R. R., BARNES, S. J., HULBERT, L. Trace-element geochemistry and petrogenesis of barren and ore associated komatiites. Canadian Mineralogist, v. 39, p. 673-696, 2001.
MACHADO FILHO, L., RIBEIRO, M. W., GONZALEZ, S. R., SCHENINI, C. A., SANTOS NETO, A., PALMEIRA, R. C. B., PIRES, J. L., TEIXEIRA, W., CASTRO, H. E. F. Projeto RADAMBRASIL Folha SF.23/24, 1983. Rio de Janeiro/Vitória. 278p. (Boletim. 32).

MACHADO, N., CARNEIRO, M. A. U$\mathrm{Pb}$ Evidence of late Archean tectonothermal activity in Southern São Francisco Shield, Brazil. Can. Jour. Earth Sci., v. 29, p. 2341-2346, 1992.

MAXWELL, C. H. Geology and ore deposits of the Alegria District, Brazil. Washinton: DNPM/USGS, Professional Paper, 1972. 72p. (Boletim 341 - I).

McBIRNEY, A. R., HUNTER, R. H. The Cumulate Paradigm Reconsidered. The journal of Geology, v. 103, p. 114-122, 1995.

McDONOUGH, W. F. et alii. K, Rb and Cs in the earth and moon and the evolution of the earth's mantle. Geochim. Cosmochin. Acta, v. 56, n. 3, p. 10011012, 1992.

OLIVEIRA, O. A. B. As falhas de empurrão e suas implicações na estratigrafia e metalogênese do Quadrilátero Ferrífero. In: CONGR. BRAS. GEOL., 34. Anais... Goiânia: SBG, 1986. v. 2, p. 1074-1087.

OLIVEIRA, A. H. de. Evolução tectônica de um segmento crustal arqueano do Cráton São Francisco Meridional. Ouro Preto: Departamento de Geologia, Universidade Federal de Ouro Preto, 1999. 104p. (Dissertação de Mestrado).

OLIVEIRA, A. H. Evolução de um fragmento do Cráton São Francisco Meridional com base em aspectos estruturais, geoquímicos (rocha total) $e$ geocronológicos (Rb-Sr, Sm-Nd, Ar-Ar, $\boldsymbol{U}$-Pb). Ouro Preto: Departamento de Geologia, Universidade Federal de Ouro Preto, 2004. 136p. (Tese de doutorado).

PADILHA, A. V. Formação Córrego dos Boiadeiros - uma seqüência komatítica na base do Supergrupo Rio das Velhas, Quadrilátero Ferrífero, Minas Gerais. In: CONGR. BRAS. GEOL., 33. Anais... Rio de Janeiro: SBG, 1984. v. 6, p. 26682679.

PADILHA, A. V., SILVA, J. R., OLIVEIRA, S. O. A unidade metavulcânica do Grupo Nova Lima no Córrego dos Boiadeiros: uma seqüência máfica-ultramáfica komatiítica na base do Supergrupo Rio das Velhas, na área central do Quadrilátero Ferrífero, MG. Rev. Bras. Geoc., v. 15, n. 1, p. 74-84, 1985. 
PADILHA, A. V., VASCONCELlOS, R. M., GOMES, R. A. A. D. Evolução geológica. In: RAPOSO, F. O. (org.) 1991a. Rio Espera, Folha SF.23-X-B-IV, Estado de Minas Gerais. Brasília: DNPM/CPRM, (Programa Levantamentos Geológicos Básicos do Brasil - PLGB), 1991. p. 119-141.

PINHEIRO, S. O. Petrologia das rochas metaultramáficas da região de Rio Manso, Minas Gerais, MG. Brasília: Universidade de Brasília, 1998. 253p. (Tese de Doutorado).

PIRES, F. R. M. Geologia do distrito manganesífero de Conselheiro Lafaiete, Minas Gerais, MG. Rio de Janeiro: Instituto de Geociências, Universidade Federal do Rio de Janeiro, 1977. 344 p. (Dissertação de Mestrado).

POMERENE, J. B. Geology and ore deposits of Belo Horizonte, Ibirite and Macacos Quadrangles, Minas Gerais, Brazil. Washington: DNPM/CPRM, Professional Paper, 1964. 84p. (Boletim 341-D).

QUÉMÉNEUR, J. J. G., BARAUD, R. Estrutura do embasamento Arqueano e geologia econômica da área pegmatítica de São João del-Rey-MG. In: SIMPÓSIO DE GEOLOGIA DE MINAS GERAIS, 2. Anais... Belo Horizonte: SBG/MG, 1983. v. 1, p. 449460.
SCHORSCHER, H. D. Komatítos na estrutura "Greenstone Belt" Série Rio das Velhas, Quadrilátero Ferrífero, Minas Gerais, Brasil. In: CONGR. BRAS. GEOL., 30. Anais... Recife: SBG, 1978. v. 1, p. 292-293.

SCHORSCHER, H. D., SANTANA, F. C., POlÔNIA, J. C., MOREIRA, J. M. P. Quadrilátero Ferrífero - Minas Gerais State: Rio das Velhas greenstone belt and proterozoic rocks. In: INTERNATIONAL SYMPOSIUM ON ARCHEAN AND EARLY PROTEROZOIC EVOLUTION AND METALLOGENESIS, 1. Anais... Salvador: SBG, 1982. v. 1, p. 43.

SEIXAS, L. A. R. Geologia e metalotectos de ouro de uma fração do lineamento Congonhas, Congonhas, Minas Gerais, MG. Brasília: Universidade de Brasília, 1988. 119p. (Dissertação de Mestrado).

SICHEL, S. E., VALENÇA, J. G. Geologia da região de Santa Bárbara, Quadrilátero Ferrífero, MG. In: SIMPÓSIO DE GEOLOGIA DE MINAS GERAIS, 2. Anais... Belo Horizonte: SBG/MG, 1983. v. 1, p. 197-208.

SOUZA FILHO, C. R. Metalogênese do ouro em zona de cisalhamento; área Tinguá, “Greenstone Belt” Rio das Velhas, MG. Campinas: Universidade de Campinas, 1991. 254p. (Dissertação de Mestrado).

TEIXEIRA, W., CARNEIRO, M. A., NOCE, C. M., MACHADO, N., SATO, S., TAYLOR, P. N. Pb, Sr and Nd Isotope Constraints on The Archean Evolution of Gneissic-Granitoid Complexes in the Southern São Francisco Craton, Brasil. Precambrian Research, v. 78, p. 151-164, 1996.

TEIXEIRA, W., SABATÉ, P., BARBOSA, J., NOCE, C. M., CARNEIRO, M. A. Archean and Paleoproterozoic Tectonic Evolution of the São Francisco Craton. In: CORDANI U.G., MILANI E.J., CAMPOS D.A. Tectonic evolution of South America. Rio de Janeiro: IGS, 2000. cap. 4, p. 101-137. 856p.

Artigo recebido em 16/09/2008 e aprovado em 16/06/2009.

\section{A REM tem novo endereço: FUNDAÇÃO GORCEIX - REM Rua Carlos Walter Marinho Campos, 57 Bairro: Vila Itacolomy 35400-000 - Ouro Preto - MG (31) $3551-4730 \quad$ (31) $3559-7408$ www.rem.com.br}

